\title{
Towards User Requirements for an Information System of the Integrated Rhine Programme
}

\author{
Thomas Usländer ${ }^{1}$, Rainer Junker ${ }^{2}$, and Ulrike Pfarr ${ }^{2}$ \\ ${ }^{1}$ Fraunhofer IOSB, Fraunhoferstr. 1, \\ 76131 Karlsruhe, Germany \\ thomas.uslaender@iosb. fraunhofer.de \\ ${ }^{2}$ Regierungspräsidium Freiburg, Bissierstr. 7 \\ 79114 Freiburg im Breisgau, Germany \\ \{rainer.junker, ulrike.pfarr\}@rpf.bwl.de
}

\begin{abstract}
The Integrated Rhine Programme (IRP) is a strategic integrated measurement programme of the German federal state of Baden-Württemberg that aims at an improvement of flood control as well as the preservation and/or the restoration of the Upper Rhine plains. The implementation of the IRP shall be supported by an integrated and sustainable Information System for the IRP (IS-IRP) as an extension of the Environmental Information System of BadenWürttemberg. This paper describes how the analysis and design methodology SERVUS is applied to gather and document the functional and informational user requirements for the IS-IRP. SERVUS denotes a Design Methodology for Information Systems based upon Geospatial Service-oriented Architectures and the Modelling of Use Cases and Capabilities as Resources.
\end{abstract}

Keywords: Integrated Rhine Programme, Environmental Information System, IS-IRP, Requirements Analysis.

\section{Introduction}

The Integrated Rhine Programme (IRP) is a strategic integrated measurement programme of the German federal state of Baden-Württemberg that aims at an improvement of flood control as well as the preservation and/or the restoration of the Upper Rhine plains [1]. Over a time period of more than 30 years it proposes and implements the creation of flood retention areas at 13 sites located in the alluvial floodplains on the Baden-Württemberg side of the Rhine. Moreover, it aims at achieving the preservation and restoration of the alluvial floodplains on the Upper Rhine to the largest possible extent. The ultimate goal entails attaining the level of flood protection that existed prior to the construction of the hydroelectric plants and locks.

Each individual measure requires an intense planning period over several years and includes the involvement of all stakeholders in the respective region including the citizens. A multitude of data has to be gathered from various sensors, databases and 
systems (e.g. surface and groundwater gauges, ecological data of fauna and flora, operational data of controlled weirs, input and output parameters of groundwater models, flood hazard and risk maps) such that an assessment and a justification of the measures is possible. Due to ongoing and lasting discussions with public and private stakeholders the argumentation line for a particular measure shall even stand up in courts after several years. Hence, there is a need for an integrated and sustainable Information System for the IRP (IS-IRP). It is designed as an extension and dedicated module of the encompassing Environmental Information System (EIS) of BadenWürttemberg [3]. One of the major design objectives is to avoid redundant data storage as far as possible.

In order to clearly understand the needs of the IS-IRP end-users as well as the capabilities of the existing EIS modules an intense requirements analysis phase is being carried out in 2011. Due to the multitude of involved persons and the interdisciplinary nature of this activity there is a need to follow a design methodology supported by an information management platform. For this purpose, the method SERVUS is being applied. SERVUS denotes a Design Methodology for Information Systems based upon Geospatial Service-oriented Architectures and the Modelling of Use Cases and Capabilities as Resources [2]. It is described in more detail in these proceedings [4].

This paper highlights the current status of the IRP implementation (section 2) and the approach of the requirements analysis (section 3). Furthermore, it presents a use case example (section 4) and concludes with an outlook about the consequences for the IS-IRP design from a broad architectural perspective (section 5).

\section{Implementation of the Integrated Rhine Programme}

By preserving the ecological goals the final objective of the IRP, once being fully implemented, is to restore protection in the Upper Rhine Valley against a 200yearly flood event. The fulfillment of this objective requires a total retention vol-

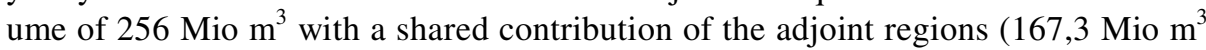
for Baden-Württemberg, 30,3 Mio $\mathrm{m}^{3}$ for Rhineland-Palatine and 58,4 Mio $\mathrm{m}^{3}$ for France).

As of today, three out of 13 measures and retention areas (polders) that are foreseen in the Framework Concept for the Integrated Rhine Programme of BadenWürttemberg are operational. See their geographical locations and implementation status in figure 1. Two of them, the polder of Altenheim and the cultural weir near Kehl/Strasbourg have successfully operated for almost 20 years now. The polder of Söllingen/Greffern was brought to completion in 2005. This type of flood control operation helps retain $67 \mathrm{Mio}^{3}$ of water [1]. The retention are of the Rheinschanzinsel is currently under construction. Over the next years, further flood retention areas will be built. 


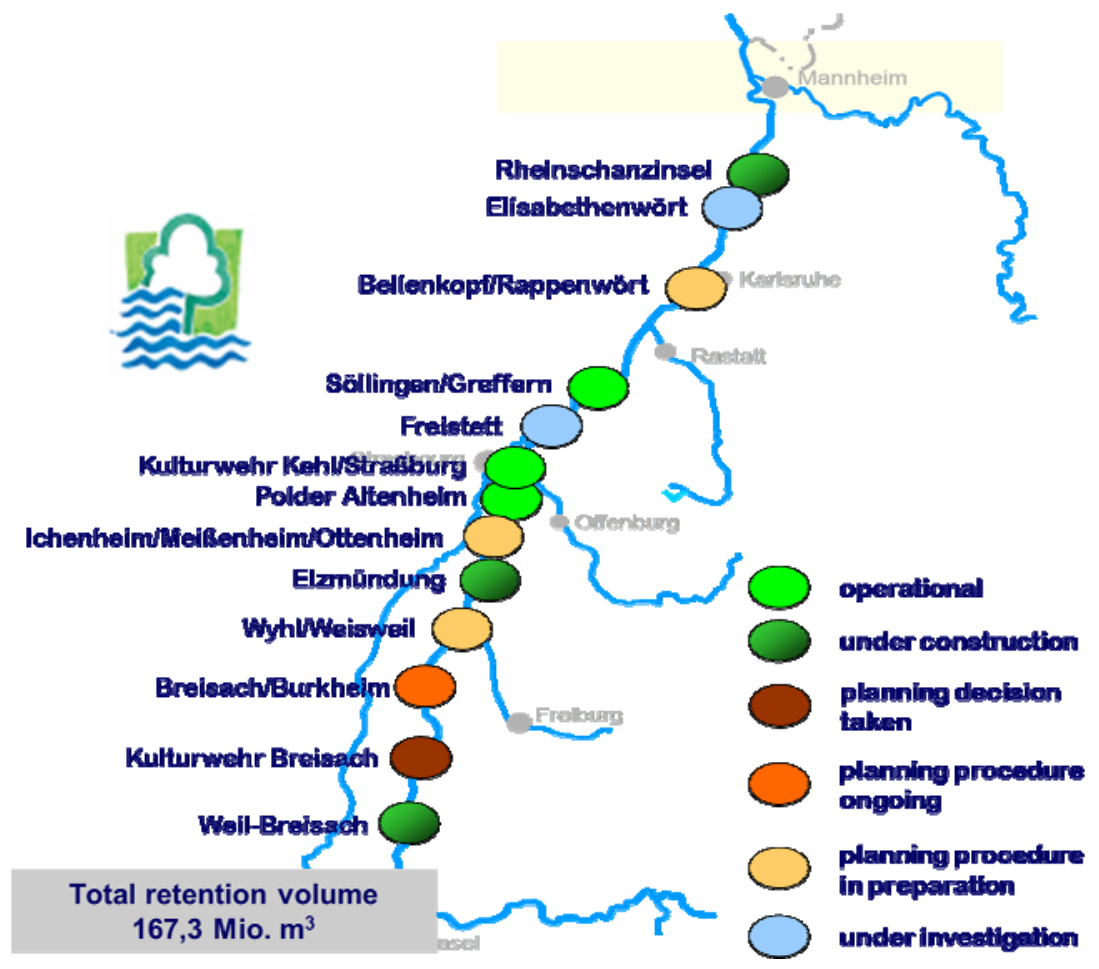

Fig. 1. Current status of measures and retention areas of the Integrated Rhine Programme

\section{Approach for the Requirements Analysis}

In the first half of 2011, an analysis project in order to identify, collect and assess the functional and informational requirements for an IS-IRP is being carried out. Hence, as of today, just early results can be presented. As a first step, preliminary use cases have been proposed by the IRP experts of the regional governmental agencies (Regierungspräsidien) of Freiburg/Breisgau and Karlsruhe whose task is the thematic planning and implementation of the IRP including the consensus finding with the various stakeholders. These use cases are classified into four major domains according to the major data categories that are concerned:

1. Operational data of retention area facilities (dams, weirs,...).

2. Groundwater and surface water monitoring data

3. Ecological sampling data (including soil data) and ecological assessment data

4. Groundwater modeling

After their identification these use cases are discussed and refined in workshops with the end-users and stakeholders. These workshops need to be facilitated and documented by a system analyst. As a starting point they are described in structured 
natural language according to a template in tabular format that just requires the name, the description, the major actors, the required information resources (input information objects) and the resulting information resources (output information objects) to be specified following the SERVUS methodology [4]. Optionally, a sequence of actions to carry out the use case may be added. It is then up to the system analyst to transform this semi-formal description into a formal representation, which, according to SERVUS, comprises a representation of the use cases and related information resources in the Uniform Modeling Language (UML). It is the advantage of this formal transition step already in an early analysis phase to detect inconsistencies and missing information as quickly as possible. The UML specification helps to (re-)discuss and check the use cases together with the thematic experts.

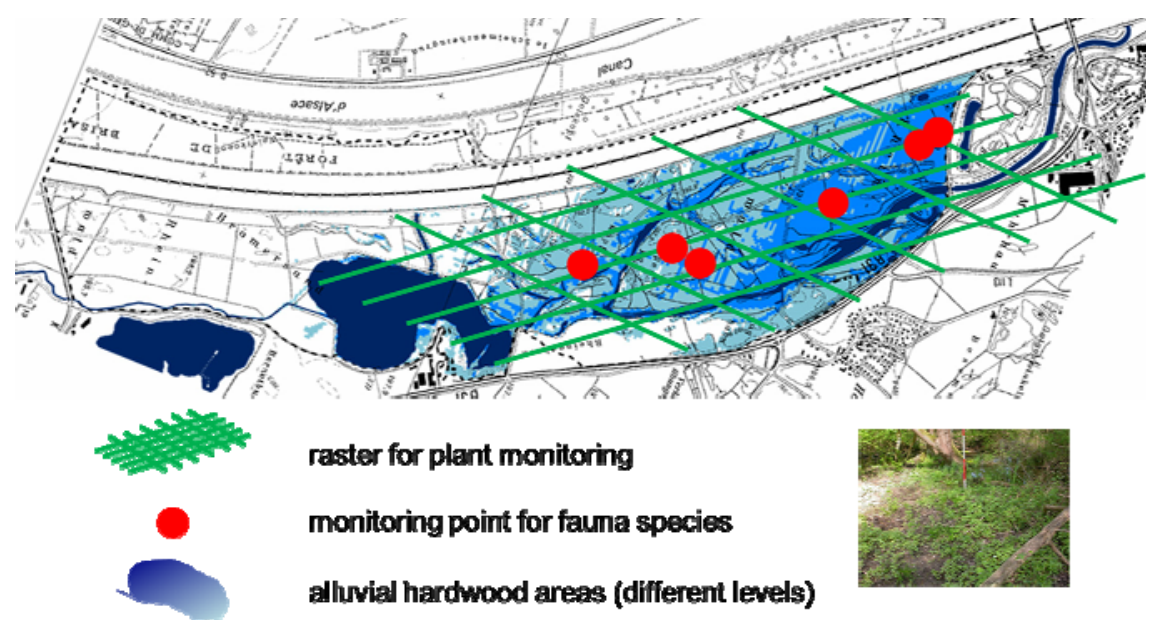

Fig. 2. Monitoring in the Alluvial Floodplains of Breisach, Germany [derived from a source figure of the RP Freiburg, 2011]

\section{Use Case Example}

As an example one use case of the ecological domain is presented in more detail. It is dedicated to fulfill statutory obligations stipulated in decisions of official planning approvals for the assessment of polder landscapes. This may be to validate that ecological floodings improve the mixture of fauna and flora species in the designated areas of the alluvial floodplains. Ecological floodings are controlled flooding events of a floodplain according to a defined procedure. Their purpose is to habituate the fauna and flora to flooding situations and, hence, to foster the formation of an alluvial forest.

Such a validation procedure requires the selection of indicator species, e.g. selected plants that characterize alluvial landscapes or epigeal fauna species such as ground beetles or snails. For these indicator species dedicated ecological monitoring programmes have to be defined. Especially, it has to be decided at which points in the alluvial floodplain the ecological observations should take place. As indicated in 
figure 2, a regular raster grid may be defined for plant monitoring, whereas individual points may be selected for fauna species.

The use case chosen is the performance of the monitoring programme as indicated above. The corresponding UML use case diagram is shown in figure 3 . It is carried out by case officers in the IRP agency. It needs, among others, to read water gauges and further input data from groundwater information systems. It requires read and write access to nature protection data, e.g. to store the observation results of the flora and fauna monitoring as explained above. As a sub-ordinate use case the production of an ecological report is illustrated. As output information resource it produces an ecological report in pdf representation format.

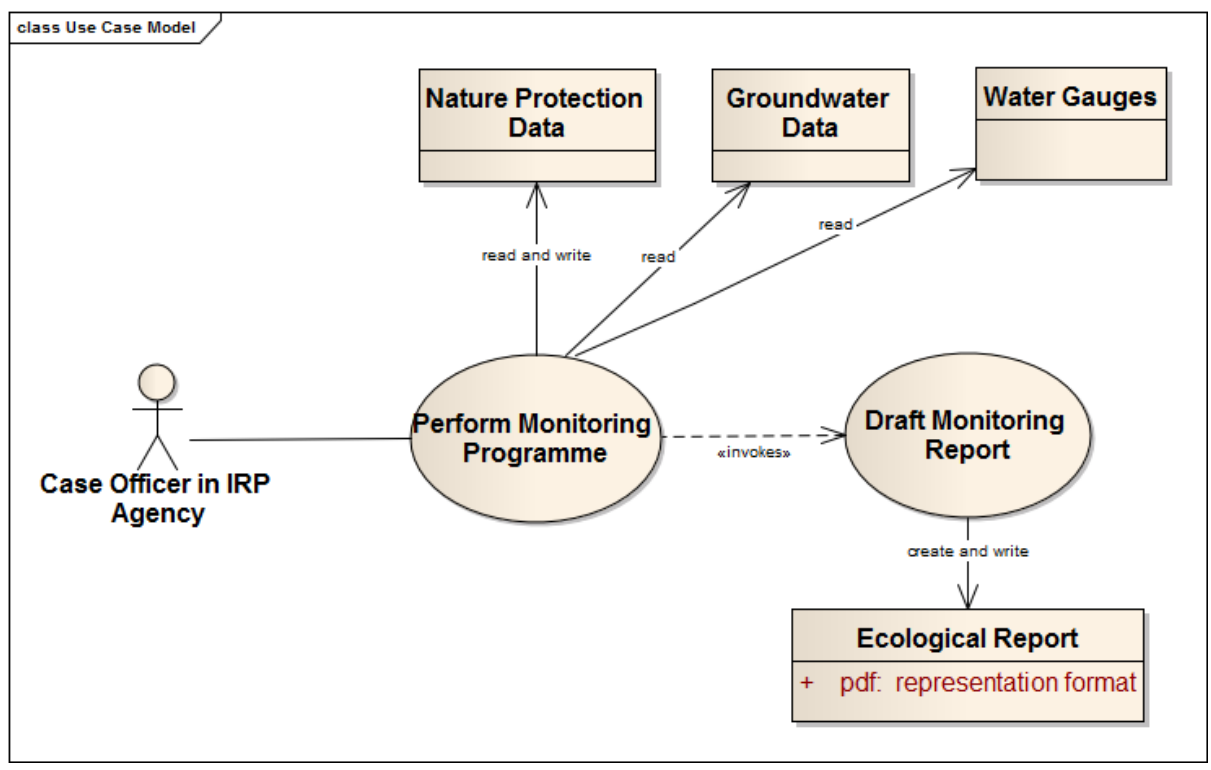

Fig. 3. Example use case "Perform Monitoring Programme" to be supported by the IS-IRP

\section{Conclusion and Outlook}

This paper discusses how the process of analyzing the user requirements for the Information System, that shall support the implementation of the Integrated Rhine Programme in the Upper Rhine valley of Germany, is being carried out. It is a report about the practical application of a scientifically sound analysis and design methodology. The use case analysis is currently being performed in 2011 for all of the data categories listed above. In several workshops that include representatives of all stakeholders and thematic experts use cases as well as requested information resources are being identified. The workshops and the whole use case analysis process is supported and documented by a Web-based information management system. As an early result it may be said that the rigid but flexible and end-user oriented methodology heavily facilitates the discussion and consensus finding between the thematic 
experts and the IT specialists. Of particular help is the immediate documentation of the use case descriptions in a Web-based content and community management system. This system is available to all project participants with dedicated read and write access rights according to their roles.

The next step will be to derive an information model for the IS-IRP and discuss the consequences and the challenges for the design of the IS-IRP system architecture in the context of the other thematic applications of the Environmental Information System of the German federal state of Baden-Württemberg [3]. Particular emphasis will be put on the question how the generic services of the EIS Baden-Württemberg may be re-used for the IS-IRP, too. Service examples to be considered are a geographical information acquisition and rendering service (disy GISterm), the capability to manage links between thematic EIS objects or the various EIS capabilities to manage semi- and non-structured information, e.g. reports and images. A further design aspect is the integration with the Web portal of the environmental ministry and the agencies based upon WebGenesis ${ }^{\circledR}$ for the offering of the public IRP information. Due to the complexity of the project and especially the multitude and heterogeneity of the input data it is expected that the analysis and design of the IS-IRP will be run in multiple iterations.

The SERVUS methodology and the design aspects for the IS-IRP may serve as a kind of template and blueprint for similar activities in other catchments and floodplains in Europe and beyond.

\section{References}

1. State Ministry of the Environment Baden-Württemberg: The Integrated Rhine Programme Flood control and restoration of former floodplains along the Upper Rhine. IRP Brochure (August 2007), http: / / www . rpbwl. de/freiburg/abteilung5/ referat53.3/faltblaetter-irp/kurz-irp-engl.pdf

2. Usländer, T.: Service-oriented Design of Environmental Information Systems. PhD thesis of the Karlsruhe Institute of Technology (KIT), Faculty of Computer Science, KIT Scientific Publishing (2010) ISBN 978-3-86644-499-7, http: / /digbib.ubka.uni-karlsruhe.de/volltexte/1000016721

3. Keitel, A., Mayer-Föll, R., Schultze, A.: Framework Conception for the Environmental Information System of Baden-Württemberg (Germany). In: Hřebíček, J., et al. (eds.) Proceedings of Towards eEnvironment, pp. 461-468 (2009) ISBN 978-80-210-4824-9

4. Usländer, T., Batz, T.: How to Analyse User Requirements for Service-Oriented Environmental Information Systems. In: Hřebíček, J., Schimak, G., Denzer, R. (eds.) ISESS 2011. IFIP AICT, vol. 359, pp. 161-168. Springer, Heidelberg (2011) 